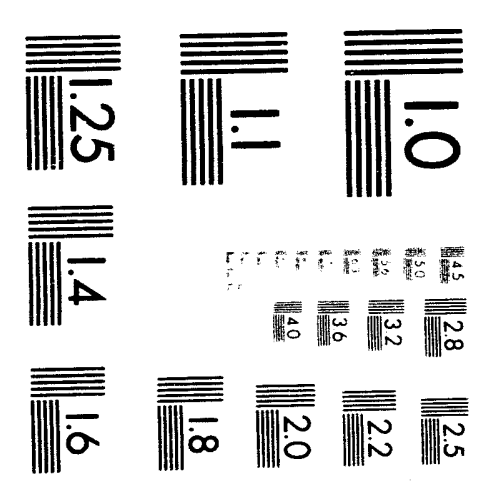



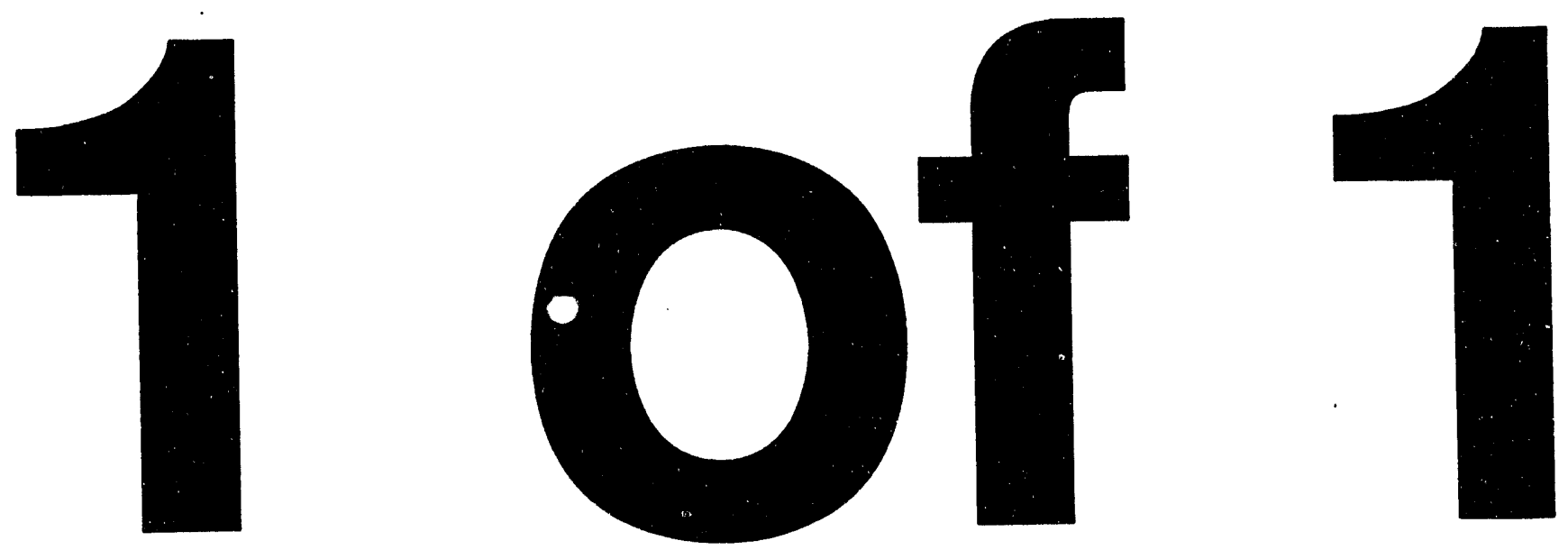
WSRC-TR-93-606

\title{
Savannah River Site DNAPL Technical Program Plan (U)
}

Savannah River Site DNAPL Task Team

\author{
Contributors: J. E. Jordan \\ B. B. Looney \\ J. Rossabi \\ C. L. Bergren
}

Authorized Derivative Classifier

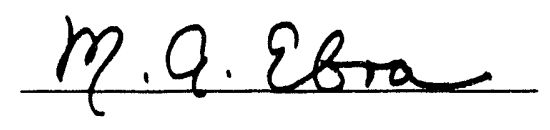

Westinghouse Savannah River Company

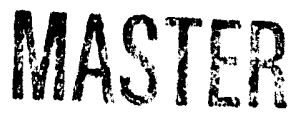
Savannah River Site Aiken, SC 29808

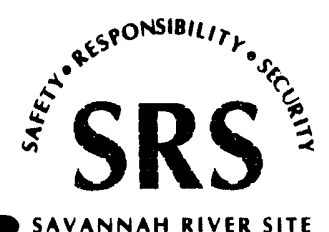

Prepared for the U. S. Department of Energy under Contract No. DE-AC09-89R1 8035.

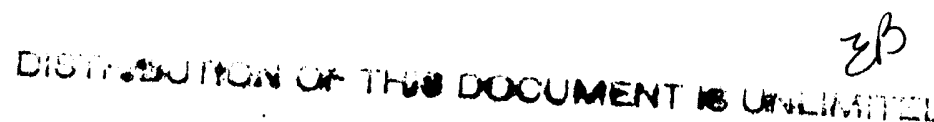




\section{DISCLAIMER}

This report was prepared as an account of work sponsored by an agency of the United States Government. Neither the United States Government nor any agency thereof, nor any of their employees, makes any warranty, express or implied, or assumes any legal liability or responsibility for the accuracy, completeness, or usefulness of any information, apparatus, product, or process disclosed, or represents that its use would not infringe privately owned rights. Reference herein to any specific commercial product, process, or service by trade name, trademark, manufacturer, or otherwise does not necessarily constitute or imply its endorsement, recommendation, or favoring by the United States Government or any agency thereof. The views and opinions of authors expressed herein do not necessarily state or reflect those of the United States - Government or any agency thereof.

This report has been reproduced directly from the best available copy.

Available to DOE and DOE contractors from the Office of Scientific and Technical Information, P. O. Box 62. Oak Ridge, TN 37831; prices available from (615) $576-8401$.

Available to the public from the National Technical Information Service, U. S. Department of Commerce, 5285 Port Royal Rd., Springfield, VA 22161 


\title{
Contents
}

\author{
Executive Summary P-1 \\ Scope P-2 \\ Objectives P-2 \\ DNAPL Characterization and Remediation Issues P-2 \\ Background P-3 \\ Status and Historical Data P-3 \\ A/M Area Remediation - Groundwater Recovery P-4 \\ Characterization and Remediation of DNAPLs P-6 \\ Characterization and Monitoring P-6 \\ DNAPL Mobilization Potential P-7 \\ DNAPL Remediation Technologies P-8 \\ Conclusions P-10 \\ Relevant SRS Publications P-11
}




\title{
Acronyms
}

\author{
BLS below land surface \\ CPT cone penetrometer testing \\ DNAPL dense non-aqueous phase liquid \\ DOE U. S. Department of Energy \\ EPA U.S. Environmental Protection Agency \\ FY fiscal year \\ GC gas chromatography \\ GC-MS gas chromatography-mass spectrometry \\ HWMF Hazardous Waste Management Facility \\ ICP-MS inductively-coupled plasma emission mass spectrometry \\ IR infrared \\ ISM industrial, scientific, and medical \\ MSL mean sea level \\ NAPL non-aqueous phase liquid \\ PCE tetrachloroethylene \\ PVC polyvinyl chloride \\ RCRA Resource Conservation and Recovery Act \\ $\mathrm{RF}$ radio frequency \\ SCDHEC South Carolina Department of Health and Environmental Control \\ SRS Savarnah River Site \\ SRTC Savannah River Technology Center \\ SVE Soil Vapor Extraction \\ TCE trichloroethylene \\ VOC volatile organic compounds \\ WSRC Westinghouse Savannah River Company
}




\section{Executive Summary}

Restoration of groundwater systems contaminated with dense chlorinated hydrocarbon compounds is one of the most significant regulatory challenges today at Department of Energy (DOE) sites and elsewhere across the United States. DOE has encouraged research into the environmental impact of these compounds at national laboratories, universities, and operating facilities. The performance of characterization and remediation technologies at dense nonaqueous phase liquid contaminated sites are studied to assist in developing enhanced contaminant recovery systems and to facilitate timely progress toward regulatory cleanup goals.

This document was developed by the environmental remediation and technology development organizations at the Savannah River Site (SRS) and is the Site technical program plan to address the remediation of residual chlorinated hydrocarbon solvents in the groundwater and the soil. These solvents are often labeled dense nonaqueous phase liquids (DNAPLs). At SRS, the primary DNAPL constituents of concern are trichloroethylene (TCE) and tetrachloroethylene (PCE); two commonly used industrial organic solvents.

The goal of the technical program plan is to provide clear objectives for DNAPL characteri aation and remediation activities at SRS. Developed by a task team of researchers at SRS, the objectives and program description document a coordinated, programmatic approach to identify solutions to the complex problem of DNAPL contamination. The purposes of this program are to expedite the development and application of technologies "or DNAPL characterization and remediation, to provide a well characterized "real" site to perform the work, and to facilitate DNAPL remediation at SRj. Given the appropriate resources, SRS will provide an intelligent application of technical skills and confidence toward the remediation of DNAPLs.

We have completed an initial characterization of DNAPLs that provides unique data on the location, nature, and extent of DNAPL occurrences at a field site. Future activities will leverage the initial characterization data for DNAPLs at SRS to demonstrate efficient progression through the characterization phase leading to cleanup. The initial characterization data provides a tool to focus this program's activities. As a result, solutions to the complex problem of DNAPL contamination will be tested and demonstrated in the most cost-effective manner. Where appropriate, the program will rely on identifying and utilizing innovative technologies developed by industry and universities. The solutions provided and data obtained to validate new technologies will directly benefit other DOE and industrial sites throughout the country. 


\section{Scope}

\section{Objectives}

The objectives of this program are the following:

- coordinate and ensure progress toward corrective action for the DNAPL portion of the $\mathrm{A} / \mathrm{M}$-Area subsurface contamination

- facilitate development and application of technologies for DNAPL characterization and remediation

- $\quad$ provide a well characterized real site to perform the work

- facilitate technology transfer of the results

\section{DNAPL Characterization and Remediation Issues}

When DNAPL is released at the surface, it migrates downward through the unsaturated zone. Some of the solvent is trapped in the soil pores by capillary forces. If large solvent volumes are released, the DNAPL will enter the groundwater. The high specific gravity and low solubility of DNAPL result in a continued downward migration, generally until an aquitard, or clay, is encountered. The residual solvent, both above and below the water table, is a long-term source of high-level contamination into the aquifer. Presumptive remediation, such as pump-and-treat systems, are not efficient in recovering this residual since it relies on the slow dissolution of DNAPL. SRS proposes to use an integrated approach, including geophysical methods, to define the chemical makeup of the contaminants and to characterize and quantify DNAPLs in the subsurface. These technologies are required to gain knowledge about the DNAPL location before proceeding to remediation technologies.

Previously collected data (in particular, explicit and unambiguous identification of DNAPL below the water table in two moritoring well sumps and auove the water table trapped in pore spaces of clays) indicate that developing and applying technologies targeted at characterization and remediation of this portion of the chlorinated solvent plume are critical to the long-term success of the Site's RCRA-permitted corrective action program. One of the conditions of the permit, written in 1983, was to continue to characterize the plume and develop and apply technologies to supplement the pump-and-treat system. The success of the demonstration will depend on developing high-quality information that will support the underground injection control (UIC) permit(s) that will be necessary for the demonstration activities and to support both the UIC and RCRA permits for full-scale application following demonstration. In this program (as in the initial characterization), SRS recommends using minimally invasive characterization techniques, such as the cone penetrometer tool, to gather subsurface information for mapping and for sampling gas, soil, or groundwater. 


\section{Background}

\section{Status and Historical Data}

Operations in $\mathrm{A} / \mathrm{M}$ Area resulted in the release of chlorinated solvents into the ground. The solvents, primarily trichloroethylene (TCE) and tetrachloroethylene (PCE), are immiscible with water and tend to form a nonaqueous phase that can migrate downward through the vadose zone and into the groundwater. The migration path is influenced by geology (e.g., clay layers), hydrology (e.g., water table location), and solvent physical/chemical characteristics. Chlorinated solvents, such as those released in A/M Area, are more dense than water. Thus, the immiscible phase is often called DNAPL. Residual subsurface DNAPL is likely at any site where significant solvent quantities have been released. Characterization of DNAPL above and below the water table is an important component in developing a comprehensive remediation system.

Since finding DNAPLs in the subsurface at SRS, environmental groups completed an initial characterization entitled Assessing DNAPL Contamination, A/M-Area, Savannah River Site: Phase I Results (U), 1992. WSRC-RP-92-1302. The primary objective of the Phase I characterization report was to assess the status of DNAPL beneath A/M Area to determine if it was mobile. Phase I characterization relied on using minimally invasive characterization technologies to gather data. The report provides a thorough background on the finding of DNAPL at SRS and the results of the Phase I characterization studies. The report provides unique data on the location, nature, and extent of DNAPL occurrences at a field site. The technologies used during the characterization include:

- $\quad$ physical and chemical measurements in existing monitoring wells (e.g., interface probe and bailer samples, and visual examination)

- cone penetrometer to provide detailed data on the geology (clay layers and lithologic controls)

- geophysical logging of existing monitoring wells to examine the well casing and formation outside the well casing for indications of DNAPL

Historical data were used to focus the study on the most promising wells and techniques. A separate phase was identified in the sumps of two wells. Both identifications were made based on the direct observation of a bottom filling bailer. The dense phases collected from these two wells were sampled and analyzed at different times to allow testing of various hypotheses for DNAPL occurrences. The observed changes in the volume and composition of the dense phase collected from the two sumps at separate times are specifically related to possible DNAPL behavior scenarios.

The data suggest that DNAPL has reached the water table only at the largest volume release areas, the M-Area Settling Basin and the A-014 Outfall. The relatively thick vadose zone beneath $\mathrm{A} / \mathrm{M}$ Area tends to limit the downward flux of DNAPL and to capture some DNAPL in layered clays. As expected, DNAPL has been observed where solvent release exceeded the capacity of the vadose zone to moderate the flux of the pure phase to the water table. The clearest evidence of DNAPL below the water table was found at the settling basin, where the separate phase was observed in two monitoring well sumps. The data collected at separate times suggest that the DNAPL below the water table occurs as relatively diffuse ganglia and/or a thin layer on the top of aquitards and that DNAPL collects in well sumps as a result of dynamic processes. One such process is the accumulation of DNAPL ganglia in the 
well sump as the well is actively purged and sampled (similar to the accumulation of sediments in the sump).

The cone penetrometer allowed refinement of the delineation of an important clay zone (the "green clay") beneath the water table. Undulations and other structural variations on top of this layer control the movement of a dense phase below the water table. Based on the cone penetrometer results, structure-controlled pathways for density-dominated transport below the water table were discerned. Two potential pathways were identified.

The geophysical logging data indicated the physical integrity of the monitoring well casing in A/M Area has not been substantially impacted by exposure to chlorinated solvents. Several logs were run; notably, a caliper log sensitive to the deformation of PVC casings as an indicator of DNAPL was performed. The monitoring wells, even those immediately adjacent to the highest volume release areas, do not show signs of mechanical instability, leakage, or other types of large-scale failure. Data from a few monitoring wells, however, provide subtle indications of potential exposure to DNAPL. The most consistent DNAPL indications were observed in monitoring wells MSB-9A and MSB-22, with less probable indications from monitoring wells MSB-10A and MSB-11A.

The DNAPL characterization provided significant insight into the nature and location of DNAPL in SRS's subsurface. In particular, the data indicate a substantial amount of DNAPL has been trapped in clays and silts in the vadose zone above the water table. Remediation of this material by soil vapor extraction (SVE) before it reaches the water table represents the first major DNAPL-targeted remediation technology. The characterization data also suggest that DNAPL below the water table in A/M Area is present as disconnected ganglia, rather than as a large, solvent-saturated layer. Future DNAPL characterization will focus on refining our knowledge of the location and nature of DNAPL in the subsurface and implementing studies to examine the efficacy of potential remediation techniques for DNAPL below the water table. As in previous work, noninvasive or minimally invasive techniques will be stressed.

\section{AM-Area Remediation - Groundwater Recovery}

In the past few years, there have been increasing concerns regarding the ability of standard groundwater recovery (or pump-and-treat remediation) systems to achieve low-target concentrations in a contaminated groundwater plume (especially at sites contaminated with DNAPLs). Studies conducted by the Environmental Protection Agency (EPA), DOE, and others document the value and limitations of pump-and-treat remediation. Typically, these systems provide mass removal and hydraulic control and produce rapid initial declines in groundwater contaminant concentrations soon after they are turned on. The removal rates and dissolved solvent concentrations from pump and treat remedies tend to stabilize over time, generally prior to reaching targeted cleanup concentrations. Residual DNAPLs above and below the water table combined with mass transfer limitations have been identified as the principal mechanisms causing the concentration stabilization. Thus, the presence of DNAPLs represents one of the most significant long-term limitations for pump and treat. Developing focused characterization and remediation techniques for DNAPLs will provide the tools necessary to augment pump and treat systems. Based on the data and studies, the most effective remediation systems will consist of pump and treat for hydraulic control and dissolved plume mass removal, combined with source/DNAPL targeted technologies to rapidly and cost-effectively remove 
large quantities of solvent (reducing the overall operating period for restoration activity).

A pump and treat system to remediate groundwater of TCE and PCE began full-scale operation in M Area in 1985. Technical performance reviews of the remediation system indicated that the system was providing hydraulic control and substantial mass removal (more than 300,000 pounds of solvent have been removed by the system to date). The concentrations and removal rates have stabilized as described above, suggesting the presence of residual DNAPL. The residual DNAPL was confirmed during well sampling in 1991. and during several vadose zone sampling programs. 


\section{Characterization and Remediation of DNAPLs}

Activities under this prograr, have been separated into the following three subtasks for management ard coordination:

- characterization and monitoring DNAPL

- evaluating DNAPL mobilization potential

- $\quad$ evaluating and demonstrating DNAPL remediation methods

Characterization activities include injection-extraction tests using alcohol and surfactant solutions to determine the presence or absence of DNAPL near existing monitoring wells, differential tracer tests to characterize DNAPL, borehole geophysical logging and crosshole seismic or electrical tomography, cone penetrometer measurements, and various other chemical and physical methods. The principal activity under the DNAPL mobilization potential subtask will be identifying critical surface tension values to avoid values associated with allowing gravity movement of DNAPL away from a remediation system during surfactant or alcohol cleanup schemes. The data will allow for estimating safe limits for interfacial tension reduction, and therefore provide important support for permitting demonstration activities. An additional goal is to investigate the phase transfer limitations on the solubilization process. This is important for both remediation demonstrations and the final interpretation of the injection-extraction tests. Innovative remediation techniques under consideration for the demonstration phase include alcohol or surfactant flushing, hydrophobic sorbents in existing boreholes, and steam flooding. Adding heat (RF, electrical, hot air) or other energy to release DNAPL from vadose zone clays was tested previously at SRS and other sites. The approach for each subtask is further described below.

\section{Characterization and Monitoring}

We propose the following three categories of complimentary characterization and monitoring technologies:

- injection/extraction/tracer tests

- geophysical techniques

- chemical and physical measurements

As demonstrated by previous characterization activities, carefully selecting and applying these various technology classes is the most efficient way to maximize the return on the investment in characterization. The technology classes are selected by answering specific questions based on specific hypotheses.

The principal objective of the injection-extraction te.t is to probe the hydraulic unit to evaluate the presence of DNAPL in the vicinity of existing monitoring wells. The test utilizes alcohol and surfactant solutions to solubilize DNAPL near the well. The solubilized DNAPL is then removed. The differences between the time-concentration response of the well effluent between water injection-extraction and the solution injection-extraction will provide a clear confirmation of the presence of DNAPL at the subject location without having to drill additional holes. Additionally, the tests will provide important information to support future alcohol or surfactant remediation. Funding for this task is based on fabricating the limited equipment for the experiment, preparing the underground injection control permit, monitoring the test with specialized VOC techniques (to account for 
the presence of surfactants), consumables, minor secondary waste disposal, and reporting. The current plans are to use (contrast and compare) water and solutions of tert-butyl alcohol and a food grade surfactant. A second activity in this category is to conduct differential tracer tests. These tests, originally developed in the oil field, examine the transport of various tracers through the ground to detect the presence of residual DNAPL. The tracers dissolve to different extents into the DNAPL. so they arrive at different times at a monitoring well. The amount of delay in the more hydrophobic tracers is related to the amount of residual DNAPL in the formation. This work will be subcontracted to a private industry or a university.

The principal objectives of the geophysical activities are to evaluate existing geophysical techniques for characterizing the nature and extent of DNAPL occurrence and to monitor DNAPL remediation tests. Borehole geophysical methods will be applied in existing (and to a limited extent, additional specially constructed) boreholes. Some of this work will focus on confirming the initial results, adding ir formation from additional logging tools (e.g., sonic log for testing grout-casing contact, and neutron log - shown at Waterloo University, Ontario, Canada to respond strongly to the presence of DNAPL). Note that this activity is focused on applying and demonstrating existing technologies from industries, universities, and national labs - not developing and constructing new logging systems. We will prepare a site description and develop a mechanism to make the site available to other researchers in DOE, EPA, etc. for testing new DNAPL-targeted geophysical logging tools. In particular, we will contact principal investigators and the program management of the in situ remediation integrated program and the VOC arid integrated demonstration programs to ensure that opportunities for collaborating, teaming, and leveraging are utilized.

This activity also will include tests of borehole-to-borehole electric or seismic tomography. Similar to a medical CAT scan or MRI, an image of the nature and extent of DNAPL at a site can be generated by sounding across a site. Both electrical and seismic methods are promising for this work. Geophysical tomography is useful because it reduces the need to drill into the most contaminated areas. This work will be performed in conjunction with the U.S. Geological Survey (USGS) with support from industry (e.g. Schlumberger and other logging companies). An interagency agreement will be needed to fund the high level of participation and collaboration with the USGS on this activity.

The principal objectives of physical and chemical characterization techniques are to utilize existing tools (depth discrete soil and water analyses, direct push methods such as cone penetrometer, and sampling from well sumps) to rapidly and cost effectively delineate DNAPL occurrence and character. Additionally, emerging technologies such as high-resolution video cameras in wells and continuous measurements using sensors will be applied as needed. This activity will be coordinated with other activities as discussed above. The funding for this activity is based on the expected level of sampling and analysis.

\section{DNAPL Mobilization Potential}

In situ surfactant or alcohol injection and extraction may be a viable detection and remediation technique for addressing DNAPL contamination in aquifers. Surfactant solutions can greatly improve DNAPL recovery of pump-and-treat systems by enhancing DNAPL solubility. Single-well surfactant injection and withdrawal has been suggested as an assessment technique to detect and quantify DNAPL saturations. An appropriate concept, 
developed by John Fountain at the State University of New York at Buffalo, is to maximize the solubilization of the DNAPL, while minimizing the impact on surface or interfacial tension (minimizing the enhanced mobility of the separate phase). In this way, the potential for gravitational loss of the separate phase solvents is minimized.

Surfactants and alcohols reduce the interfacial tension (IFT) between the aqueous solution and the DNAPL. This IFT reduction can lead to the mobilization of DNAPL blobs if the balance between gravitational forces and capillary forces is changed sufficiently. Little work has been done to quantify the point at which an IFT reduction will allow the initiation of gravity-driven DNAPL mobilization. The capability to quantitatively predict the conditions under which mobilization becomes a concern could greatly reduce remediation costs by reducing lab tests required to demonstrate mobility control at any given site. It would also allow for optimizing surfactant solution characteristics to achieve the highest solubilization, while minimizing risk of losing mobility control over the DNAPL. Developing specific information on this issue is viewed as a critical issue to designing and permitting DNAPL remediation systems.

This subtask will be principally laboratory and pilot-scale studies examining the impact of various surfactant and/or alcohol solutions on the stability of residual DNAPL in a variety of porous media (e.g., sands and clays) with varying degrees of layering and anisotropy. We propose to use a noninvasive technique (e.g., gamma-gamma logging or high-energy E-M waves from a synchotron source) capable of accurately quantifying DNAPL saturation in the test cells to determine the DNAPL distribution in the bench- or pilot-scale porous medium. A pore scale network model and predictive equations for critical IFT values will be developed based on the results. Several universities and companies are being solicited through competitive bidding to provide a detailed test plan.

\section{DNAPL Remediation Technologies}

The principal remediation test that will be performed under this program will be an alcohol or surfactant flushing experiment. The flushing solution selected for the demonstration will be based on the results of the injectionextraction characterization and on modeling performed by investigators at South Carolina regional universities. We anticipate that an oil field type "six spot" pattern will be use for the test. This pattern consists of six injection wells located in the shape of a hexagon surrounding a central extraction well. The solubilizing solution will be added through the injection wells and will be removed through the extraction well. Data from extensive oil field technologies (private sector) will be used to support the test and to help obtain the necessary underground injection control permit (by helping to demonstrate minimal undesirable migration potential). The diameter of the system and the precise location of the screen zones will be determined based on the results of the characterization activities.

Two additional technologies will be examined under this subtask. These technologies are remediation in existing monitoring wells using hydrophobic sorbent tubes and enhanced vacuum extraction from clays above the water table using vibration energy. The hydrophobic sorbent tubes (pillows or pigs) are normally used for spill control. They have a strong affinity for oils and solvents and exclude water because of the small pore size. The pig will selectively capture and remove blobs of DNAPL that enter the well. If the DNAPL phase is sufficiently continuous, the capture will induce a flow of the separate phase toward the well. This "pumping" uses no energy and 
occurs at a rate consistent with release rates from the formation. Each 3.5" diameter pig is expected to capture approximately $3 \mathrm{~L}$ of pure DNAPL. The principal objective of the enhanced vacuum extraction task is examining the potential costs and benefits of adding vibrational energy to enhance the release of residual DNAPL in clays above the water table; this will lead to a decision on whether to use this system. If a simple field test (coupled to the planned vacuum extraction activities) can be designed based on the examination, it will be performed.

Vacuum extraction and heating technologies to enhance vacuum extraction were previously demonstrated to address the residual DNAPL contamination above the water table. As a result of the tests, full-scale vacuum extraction is permitted and will be implemented during the next fiscal year as part of the Environmental Restoration Program. The RCRA permit for the site requires periodic reexamination of the effectiveness of the remediation system(s) and selection of additional or newly available technologies as appropriate. The results of a vadose heating demonstration test will be incorporated into the alternatives analysis at the next reexamination. 


\section{Conclusions}

Information developed during this program will facilitate the following:

- developing and demonstrating innovative characterization and monitoring technologies, as needed, to support evaluation of the nature, extent, and behavior of DNAPLs in the subsurface

- developing the technical basis for selecting remediation methods for DNAPL above and below the water table

- demonstrating the selected technologies

We propose active technology transfer through peer reviewed publication of the results, the WSRC Technology Transfer Office, and other mechanisms. The project organization maximizes the potential for success of the innovative characterization, monitoring, and remediation technologies because they can be planned and targeted based on existing data. The initial characterization, while insufficient to develop final remediation plans, is unique in this country - providing the best available information about the extent and nature of DNAPL distribution from a major facility in a real setting. The quantity and type of additional data proposed is specifically targeted to lead to field-scale remediation technology demonstration activities. Universities, industrial partners, and outside experts will be included in planning and performing all activities - maximizing the credibility of the process and the potential for correct decision making and successful demonstration, as well as enhancing technology transfer. The demonstration will provide a timely transfer of new technologies to environmental restoration groups at SRS for use in full-scale remediation projects. In addition, the formal technology transfer function at SRS and meetings such as the ER Technology Information Exchange will be used to transfer successful technologies to other DOE sites and outside the DOE complex. 


\section{Relevant SRS Publications}

1. DOE, 1992. Assessing DNAPL Contamination, A/M Area, Savannah River Site: Phase I Results. Westinghouse Savannah River Company, WSRC-RP-92-1302.

2. Eddy, C. A. and Looney, B. B., 1993, "Three Dimensional Digital Imaging of Environmental Data: Optimization of Variable Parameters during Three-dimensional Grid Calculations". International Journal of Geographic Information Systems. v. 7, no. 2, p. 165-172.

3. Eddy, C. A. and Looney, B. B., 1992, "Three-Dimensional Imaging of Environmental Data: Optimal Selection of Gridding Parameters for Volumetric Calculations" [abs.]. EOS Transactions of the American Geophysical Union. v. 73, no. 43, p.230.

4. Eddy, C. A., Looney, B. B., and Kaback, D. S., 1992, “Comparison of Innovative Depth Discrete Sampling Technologies for Sediments and Groundwater for Environmental Characterization", Proceedings of the 1992 Waste Management and Environmental Sciences Conference, Puerto Rico, p. 124-133.

5. Eddy, C. A., Looney, B. B., Dougherty, J. M., Hazen, T. C., and Kaback, D. S., 1991, Characterization of the Geology. Geochemistry, Hydrology and Microbiology of the In-situ Air Stripping Demonstration Site at the Savannah River Site. Westinghouse Savannah River Company, WSRC-RD-91-21.

6. Looney, B. B., Pickett, J. B., and Malot J. J., 1991, Pilot Test of a Vacuum Extraction System for Environmental Remediation of Chlorinated Solvents at the Savannah River Site. Westinghouse Savannah River Company, WSRC-RD-91-19.

7. Looney, B. B., Eddy C. A., and Sims W. R., 1993, "Evaluation of Headspace Method for Volatile Constituents in Soils and Sediments". Proceedings of the National Symposium on Measuring and Interpreting VOCs in Soils: State of the Art and Research Needs. U. S. Environmental Protection Agency, January 12-14, 1993, Las Vegas NV.

8. Nichols, R. L., Looney, B. B., and Huddleston, J. E, 1992, Three Dimensional Digital Imaging, Environmental Science and Technology. v. 26, no. 4, p. 642-u49.

9. Rossabi, J., in press, "The Savannah River Technology Center Environmental Monitoring Field Test Platform", Proceedings of the Third International Symposium-Field Screening Methods for Hazardous Waste and Toxic Chemicals. Las Vegas, Nevada.

10. Rossabi, J., in press, "In situ, Subsurface Monitoring of Vapor Phase TCE Using Fiber Optics", Proceedings of the Third International Symposium-Field Screening Methods for Hazardous Waste and Toxic Chemicals, Las Vegas, Nevada.

11. Rossabi, J., Looney, B. B., Riha, B., Ferrelli, A., and Smith, N., 1992, "The Influence of Surface Pressure Fluctuations on 
Surface/Subsurface Air Migration" [abs.]: EOS Transactions of the American Geophysical Union. v. 73, no. 43, p.233.

12. Rossabi, J., 1992, , 'er Optic Sensors for Environmental Application: A Brief Review. Westinghouse Savannah River Company, WSRC-RP-92-471.

13. Rossabi, J., Eckenrode, B. A., and Owens, B., 1992, Onsite Well Screening with a Transportable Gas Chromatography/Mass Spectrometer System. Westinghouse Savannah River Company, WSRC-RP-91-603. 

